\title{
Effect of annealing temperature on the microhardness of tungsten carbide coatings deposited by RF sputtering
}

\author{
Mourad Khechba', Beddiaf Zaidi²*, Chander Shekhar, \\ Maria Plamenova Nikolova ${ }^{4}$
}

\author{
'Laboratoire des couches minces \& interface, Université Constantine 1, Constantine, Algérie (mourad.khechba@gmail.com) \\ 2PRIMALAB Laboratory, Department of Physics, Faculty of Material Sciences, University of Batna 1, Batna, Algeria (zbeddiaf@gmail.com) \\ ${ }^{3}$ Department of Applied Physics, Amity University Gurgaon, Haryana, India-122413 (cshekhar@ggn.amity.edu) \\ ${ }^{4}$ Department of Material Science and Technology, University of Ruse, Bulgaria (mpnikolova@uni-ruse.bg) access
}

\begin{abstract}
A systematic study on the effect of annealing temperature on the hardness of Tungsten carbides (WC) coatings were deposited by RF magnetron sputtering onto steel substrate (XC70) was carried out in this study. The as deposited coatings were heat treated in vacuum at temperature range between $500-1000{ }^{\circ} \mathrm{C}$ for 25 minutes. The mechanical properties of these coatings were investigated by Vickers microhardness tests at different applied loads and penetration depth of the indenter into the coatings. The microhardness tests were carried out as a function of applied loads between $10-1000 \mathrm{~g}$, annealing temperature in the range of $500-1000{ }^{\circ} \mathrm{C}$, and penetration depth of the indenter up to $25 \mu \mathrm{m}$. The microhardness of the coatings was found to decrease as a function of applied load and the penetration depth. The microhardness initially increases and thereafter decreases as the annealing temperature increases.
\end{abstract}

Keywords: Microhardness, WC, steel (XC70), Coating, Mechanical properties.

\section{INTRODUCTION}

Tungsten carbide is a material used for a number of industrial applications and it is characterised by its high strength, toughness and hardness. Deposition of the tungsten carbide coatings on different materials have shown to enhance the tribological properties such as surface hardness and toughness significantly and the materials systems have shown to outperform many steel product equivalents [1-4]. Many refractory borides, carbides and nitrides have shown to improve the mechanical properties of different materials employed for the industrial applications. Tungsten carbides (WC and $\mathrm{W}_{2} \mathrm{C}$ ) are among these refractory materials and are characterized by: i) a relatively high hardness reaching $-2200 \mathrm{Kg} / \mathrm{mm}^{2}$ and $3000 \mathrm{Kg} / \mathrm{mm}^{2}$ respectively, ii) a very high melting temperature $\left(\approx 2800{ }^{\circ} \mathrm{C}\right)$, iii) a low coefficient of thermal expansion [5], iv) an extremely high modulus of elasticity and good thermal conductivity $[6,7]$. WC and $\mathrm{W}_{2} \mathrm{C}$ are extra hard compared to the base metal W having hardness of the order of $360 \mathrm{Kg} / \mathrm{mm}^{2}$. The present study reports the variation of the microhardness of WC and $\mathrm{W}_{2} \mathrm{C}$ coatings as a function of the applied load, penetration dept and annealing temperature.

\section{EXPERIMENTAL}

Tungsten carbide coatings were deposited by RF magnetron sputtering on steel substrate (XC70) using WC target. The substrate temperature was kept at $500^{\circ} \mathrm{C}$ and the pressure for the deposition was $10^{-7} \mathrm{mbar}$ and the deposition time is 35 minutes. The details of the thin film deposition is samilar to procedure reported in the literature [8]. The thickness of the tungsten carbide coatings is about $5 \mu \mathrm{m}$ approximated from the time of the deposition. The as deposited samples [W $(5 \mu \mathrm{m}) / \mathrm{XC} 70$ ] were heat treated in vacuum at temperature range $\left(500-1000^{\circ} \mathrm{C}\right)$ for $25 \mathrm{~min}$ [9]. Thereafter the films were subjected to the microhardness measurements by Vickers micro-hardness tester applying the load in the range of between $10 \mathrm{~g}$ and $1000 \mathrm{~g}$. Similar procedure were adopted to characterize the thin films at different annealing temperatures applied load and the penetration depth of the indenter.

\section{RESULTS AND DISCUSSION}

Fig. 1 shows the variation of the microhardness of the samples as a function of the annealing temperature. It is clear that the microhardness increases rapidly to $700{ }^{\circ} \mathrm{C}$, then rapidly decreases to $900^{\circ} \mathrm{C}$. and then slowly increases. The value 
of the microhardness of the non-annealed sample is $312 \mathrm{~kg} / \mathrm{mm}^{2}$ (comparable to that of solid tungsten). However, after annealing, the microhardness values are distinct; the microhardness becomes maximum and reaches $720.61 \mathrm{~kg} / \mathrm{mm}{ }^{2}$ and then decreases rapidly to $391.91 \mathrm{~kg} / \mathrm{mm}^{2}$ at $900^{\circ} \mathrm{C}$. The increase in the micro-hardness is thought to be due to the decrease in the grain size of the coatings [8]. From this temperature, the hardness slowly increases to $442.02 \mathrm{~kg} / \mathrm{mm}{ }^{2}$ at $1000^{\circ} \mathrm{C}$. It is noted that the values of the microhardness throughout the annealing temperatures are lower than those of the WC solid masses $\left(-2200 \mathrm{~kg} / \mathrm{mm}^{2}\right)$ And $\mathrm{W}_{2} \mathrm{C}\left(-3000 \mathrm{~kg} / \mathrm{mm}^{2}\right)$. The growth of the microhardness of the coatings, especially above $800{ }^{\circ} \mathrm{C}$, is certainly due to the formation and growth of the WC and $\mathrm{W}_{2} \mathrm{C}$ carbide. The increase in the hardness beyond $1000^{\circ} \mathrm{C}$ is due to the formation of the hard grains of $\mathrm{WC}$ and $\mathrm{W}_{2} \mathrm{C}$ due to annealing at $1000^{\circ} \mathrm{C}$

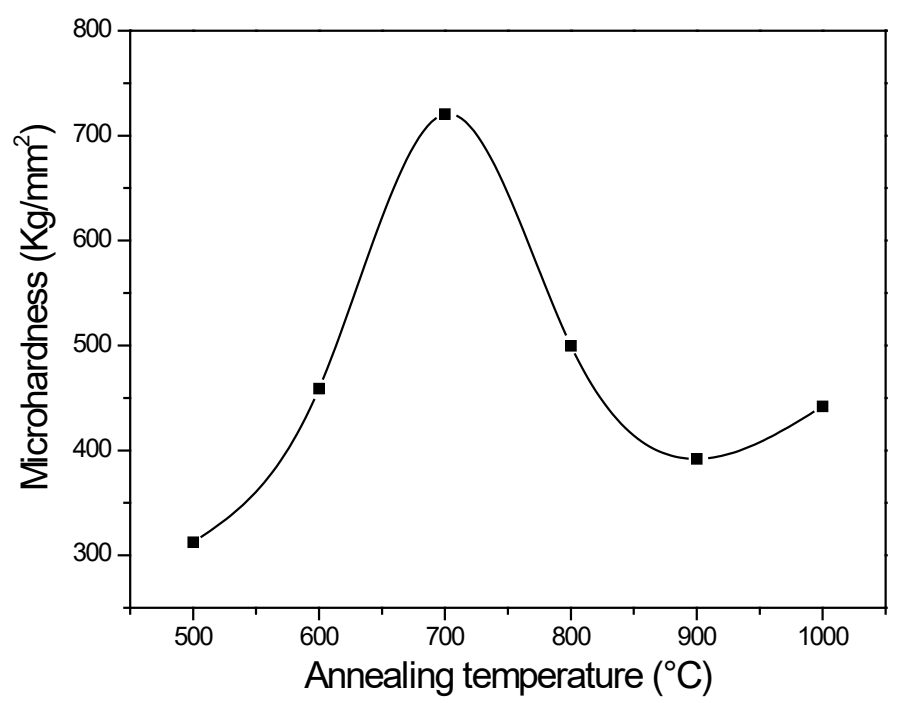

Fig. 1: Variation of the microhardness as a function of the annealing temperature

Fig. 2 shows the variations in the microhardness of the samples as a function of the applied load. One notices that the curves have almost the same pace. They decrease rapidly when the applied load increases to $\sim 0.3 \mathrm{Kg}$, which can be called critical load and then slowly decrease to $1 \mathrm{Kg}$ with values very close. The microhardness takes values on the surface of the samples that are greater than those of volume, whatever the annealing temperature: For the unannealed sample. However, on the bearing, that is to say by volume, it is less than $200 \mathrm{~kg} / \mathrm{mm}^{2}$, a value comparable to that of the substrate.

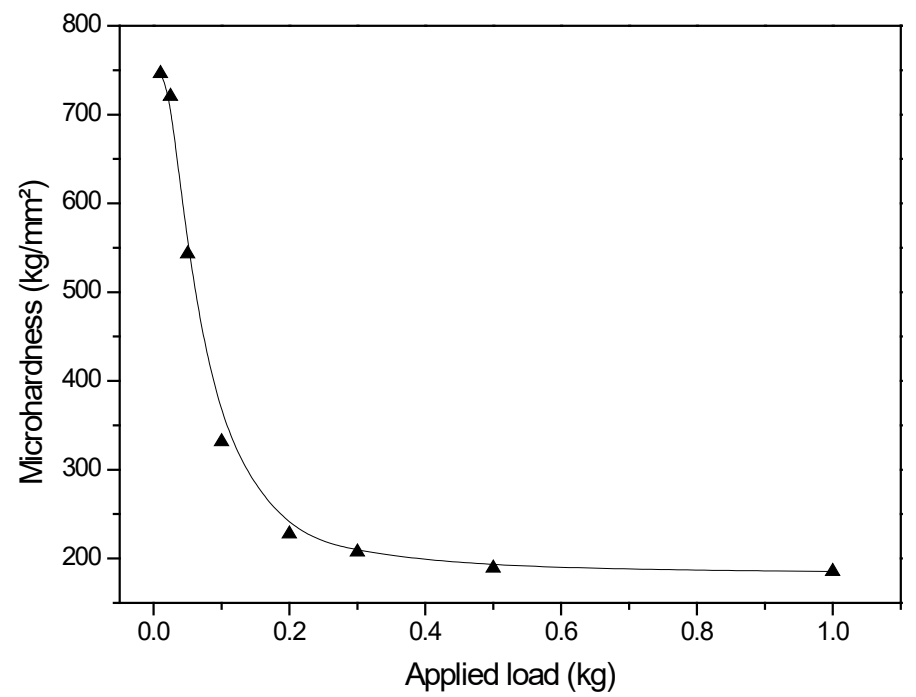

Fig.2: Variation of microhardness as a function of the applied load after annealing at $700{ }^{\circ} \mathrm{C}$ for $25 \mathrm{~min}$.

For samples annealed between 900 and $1000{ }^{\circ} \mathrm{C}$, the microhardness is considerable at the surface, whereas on the plates, it decreases but does not reach the value $200 \mathrm{Kg} / \mathrm{mm}^{2}$. This is mainly due to the presence of tungsten carbides at the interface (coating / substrate), as evidenced by X-ray diffraction [9].

Fig. 3 Shows the variations of the microhardness as a function of the depth of penetration of the indenter. It can be noted that the microhardness in all cases decreases from the free surface to the volume, a rapid decrease to certain depths and then the decrease becomes slow. This change in rate of decrease is due to the effect of the substrate on the micro-hardness, and when the depth is large, the values of the microhardness obtained are very close to that of the substrate [10, 11]. It 
is also noted that the depth after which the hardness decreases slowly, depends on the annealing temperature.

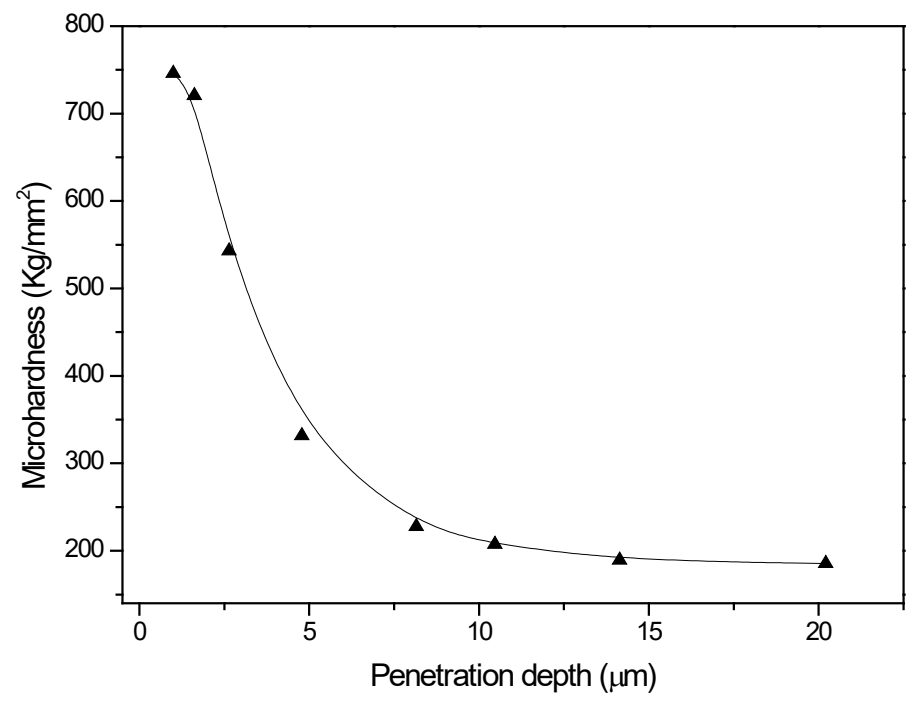

Fig.3: Variation of microhardness as a function of penetration depth after annealing at $700{ }^{\circ} \mathrm{C}$ for $25 \mathrm{~min}$.

\section{CONCLUSION}

The samples of tungsten films deposited on steel substrate (XC70) were subjected to heat treatments in vacuum at various temperatures from $500-1000{ }^{\circ} \mathrm{C}$ for 25 minutes duration. The annealing temperature greater than or equal to 700 ${ }^{\circ} \mathrm{C}$ promotes the reaction between the constituents of the sample; $\mathrm{W}$ and substrate; The microhardness samples decreases with increasing the applied load and the depth of penetration until substrate. The growth of the microhardness of the coatings, especially above $800^{\circ} \mathrm{C}$, is certainly due to the formation and growth of the $\mathrm{W}_{2} \mathrm{C}$ carbide and has interesting mechanical characteristics.

\section{REFERENCES}

[1] A. Jafari, R. Alipour, M. Ghoranneviss, A. H. Ramezani, J Inorg Organomet Polym 26 (2016) pp 384-393.

[2] L.C. Agudelo-Morimitsu, J. De La Roche, A. Ruden, D. Escobar, E. Restrepo-Parra, Ceramics International 40 (2014) pp 7037-7042.

[3] F.M. El-Hossary, N.Z. Negm, Appl. Surf. Sci. 181 (2001) pp 185-190.

[4] E. A. Popova, A. V. Dolmatov, A. V. Kiselev, L. E. Bodrova, S. A. Petrova, E. A. Pastukhov, N. A. Vatolin, Russian Metallurgy (Metally) 6 (2006) pp 487-491.

[5] P. Hidnert, Journal of Research of the National Bureau of Standards 18 (1937) pp 47-52.

[6] M. Factor and I. Roman, Surf. Coat. Technol. 132 (2000) pp 181-93.

[7] G. Barbezat, A.R. Nicoll, and A. Sickinger, Wear 162-164 (1993) pp 529-37.

[8] A.S. Kurlov, A.I. Gusev, Inorganic Materials 42 (2006) pp 121-27.

[9] B. Zaidi, M. Khechba, C. Shekhar, I. Saouane, R. Li, Int. J. Adv. Manuf. Technol. 89 (2017) pp 1837-1840.

[10] P. Chivavibul, M. Watanabe, S. Kuroda, and K. Shinoda, Surf. Coat. Technol. 202 (2007) pp 509-521.

[11] J. Nerz, B. Kushner, and A. Rotolico, J. Thermal Spray Technol. 1 (1992) pp 147-152. 